\title{
Socio-Sexual Education Is Best Addressed as a Field of Study
}

\author{
Paul A. Wagner ${ }^{1}$ \\ ${ }^{1}$ Department of Leadership, Educational Psychology and Policy Analysis, University of Houston, Houston, \\ Texas, USA \\ Correspondence: Paul A. Wagner, Senior Ranking University Professor, Department of Leadership, Educational \\ Psychology and Policy Analysis, University of Houston - Clear Lake, 338, Houston, Texas 77058-1098, USA. \\ Tel: 1-281-283-3571.
}

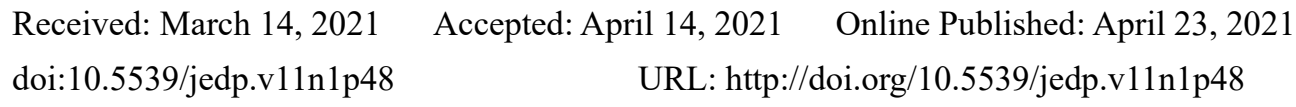

\begin{abstract}
Sex education typically claims to be value free. The focus of attention in this article is that sex education represents an extraordinary "teachable moment" for helping students consider the qualia of human engagements at a multiplicity of levels. Qualia is a term for the feel and hence the value of experience. Learning about the process of copulating machinery reveals little about the "feel" of sexual experience.

Sex education should address issues students will continue to confront for the rest of their lives. Typically, students seem to waffle their way through sexually relevant encounters. Allure and fear are relevant emotions students should be mindful of when considering socio-sexual engagements of any kind. Consequently, rather than focus exclusively on sexual behavior and its consequences, educators should focus on what I have previously introduced as socio-sexual education. Socio-sexual education involves game-theoretic considerations but goes further than mere cost/benefit analysis. Socio-sexual education should focus student attention on understanding of sex and social engagements generally. People live in and through their experiences and not as mere spectators of some narrative in which experience is written about. Learning to understand socio-sexual experiences allows subsequent social and sexual adjustments for improving lived experience over a lifetime. Sex education then should broaden to socio-sexual instruction and reflection.
\end{abstract}

Keywords: game theory, knowledge silos, phenomenology, qualia, socio-sexual relations, instruction

\section{Sexuality: A Practice, a Behavior, and an Experience}

Students often look forward to their first experience with sex education albeit with a bit of trepidation for some. Unfortunately, for most their first experience with sex education is disappointing. Students want to know what all the fuss is about (Wagner \& Siegel, 1988a). They want to know why even a brief contact with others they fancy causes their heart to beat faster. They want to know why kissing some people is exhilarating, kissing others terrifying and kissing still others feels no different than kissing their own hand (Wagner, 2016; Wagner, 2017). These are the much-anticipated understandings most students hope will be revealed in a sex education course.

Their hopes and anticipations are seldom realized (Ashcroft, 2003). Instead, they are taught a sterile, biological account of human copulation and rates and risks of associated diseases (Meeker, 2001). Nearly all the questions they had when beginning sex education remain unanswered, sidelined in favor of teaching the consequences of reckless behavior. Oddly, the concepts of reckless and inappropriate behavior are rarely defined any further than as passing allusions when instructors describe physiological processes and warn about the costs of unwanted pregnancy and disease (Symons, 1979; Wolfe \& Blanchett, 2003).

\section{Sex Education: A Practical Field of Study}

Years ago, curriculum theorist Paul Hirst made an important distinction for educators between subjects and fields of study (Hirst, 2010). Examples of subjects are academic disciplines such as math or chemistry. In subjects, Hirst explains, there are basic facts and regulatory rules of inference - making germane to the subject. These subjects tend to become self-limiting much as a missile silo contains only what it was built for and nothing more. In contrast, in fields of study, such as say, ecology or biochemistry, facts and inferential practices are drawn together from more than one academic discipline. A multitude of facts, inferential practices, skills, dispositions, values, and attitudes may be drawn upon to caste a far-reaching net of, in this case, sexual experience (Hirst \& Peters, 2011). 
Think of Hirst's distinction between subjects and fields of study as offering a heuristic. For example, as of now, subject matter is often taught in the confines of a silo-like environment. Mathematics typically comes to mind. Today's math curriculums tend to be rubric-driven and aligned with standardized tests. The application of the silo curriculum to worldly survival is talked about but not much else (Wagner \& Freedman, 1985). The silo curriculum is for success on standardized tests and not for navigating the world with mathematical capacities easily at hand. Fields of study such as environmental ecology, biochemistry, cast a broader net and tend to focus more on applied tasks yet, they are becoming increasingly infrequent (Wagner, Johnson, Fair, \& Fasko, 2017; Wagner, 1999).

Sex education is not a subject and is ill-suited for silo scaffolding. Sex education is by its nature, a field of study. It has already been suggested that sex education can be enhanced by blending mathematical game theory with the socio-sexual decision experiences that involve popularity and moral values such as respect for self and others (Wagner, 2011). These things matter greatly to developing teenagers (Buss, 1988; Todd \& Miller, 1999). The rigorous thinking of mathematical game theory is meant to free students from mere impulse or reactionary judgements (Gilovich, Griffin, \& Kahneman, 2002; Pollock, 1984). So too, socio-sexual education should cross the social science and humanities as well - especially the humanities, if students are to be released from the demands of instinct and impulsiveness. From Socrates to Robert Nozick, the craft of living an examined life does not come about easily (Gigerenzer, 2014; Nozick, 1989; Wagner \& Dede, 1986).

\section{The Challenge of Moving Beyond the Silo}

Students need and deserve something more robust than a silo approach subservient to some standard metric if sex education is to prepare them for the world now and for life ahead (Wagner \& Dede, 1986). To start, sex education must be designed as a field of interest covering impending socio-sex experience students face now and for the rest of their lives. Sexual experience is more than a subject matter with its own inferential rules, facts, and values (Bandura, 2006). To be both practical and fulfilling, sex education must go more to the heart of the matter namely, lived experience including discussions of prescriptions, prohibitions, dispositions, and attitudes involved in the whole range of socio-sexual experience (Fowers, Lyons, Montel, \& Shaked, 2001; Wagner, 1981). In the silo format sex education becomes a sort of sterile biology class with posted warnings about so-called risky behavior. In contrast, socio-sexual instruction encompasses a field of study cutting across most of the school curriculum. The focus should be on equipping students with a set of mindware (Wagner et al., 2017) sufficiently robust for addressing challenges posed by a broad field of inquiry Wagner, 1977). This is how sex education becomes socio-sexual education encompassing a broad range of understanding and slow-thinking inferential tools as Nobel Laureate, Daniel Kahneman might say.

For Kahneman, thinking can be largely split between fast thinking and slow thinking (Kahneman, 2011). Fast thinking is built on simple ready to use algorithms and heuristics. People use fast thinking to get through much of their day. In contrast, slow thinking is required when the challenge is to figure something out. Slow thinking involves constructing protocols for evaluation, and heuristics for immediate action when necessary. In short, slow thinking is a matter of applying the Law of Figuring Things Out (LFTO). The LFTO involves meta principles for deciding on lower order regulatory values and practices of thinking (Wagner \& Fair, 2020; Wagner, Johnson, Fair, \& Fasko, 2018).

The warning of standard sex education often focus on fast thinking: "Whoa, don't do that!", "Stop!!” Remember how babies are made!", "This risk is too costly!" These fast-thinking platitudes rarely succeed in helping students manage the challenge of their growing socio-sexual world. The socio-sexual world is much more demanding of slow- thinking especially in puberty and prepubescent years when young people are faced with re-making much of their previous social, worldview. Others no longer have "cooties" and popularity is more alluring than ever before despite the costs of risky or meaningless sexual engagements). Here, slow thinking is invaluable (Wagner, 2020). Slow thinking demands framing challenges clearly and then using the LFTO to draw on a host in concepts and regulatory mindware to reach plausible conclusions optimizing expected utility for self at least and perhaps, others as well. As part of their application of the LFTO, students must decide whether the social challenge represents a zero-sum game or a non-zero-sum game. (Wagner \& Fair, 2020)

In socio-sexual education, the field of study is designed to cut across the curriculum. Mathematical game theory and economic decision theory expand sex education safely beyond what sex educators want to teach. Safely in this instance means without agitating other stakeholders in public education. The socio-sexual world is largely about things such as popularity, self-esteem, character, reputation, adjustment to evolving body types and finally to unexpected hormonal driven impulses. Only the last two of these can be easily aligned with uncontroversial multiple choice test items.

Previous work has addressed the need for socio-sexual education to broaden its swath across mathematics and into 
game theoretic slow-thinking thought constructions (Wagner, 2011). But the encompassing swath of socio-sexual education must be made broader yet. It must include literature perhaps foremost and then history, art, philosophy and the attendant social sciences as well. In the end, every element of the public-school curriculum must be acknowledged as having some role in the socio-sexual education of students.

\section{Qualia}

Qualia is the name for the feel of experience. Philosophers Hilary Putnam, Thomas Nagel and then Frank Jackson are often cited as the progenitors of contemporary thinking about qualia (McCullough, 2020; Jackson, 1998; 1982). Nagel, 1991; Putnam, 1981). Putnam and Nagel for example, both contend that even if neurologists knew all about the evolution and biochemistry of bat, mental life they still would not know what it feels like to be a bat. Certainly, there must be a feel for what it is like to be a bat. And even if there were no such feel, neurologists could never know that either inasmuch as neurologists are not bats. The presence or absence of these feels are the phenomenology of the experience or more simply the frothy element of experience, qualia.

To illustrate the poignancy of the problem of qualia for humans, Jackson proposed his famous problem about Mary. Mary is imagined growing up in a world of black, white and shades of grey. She has never seen another color. She has read all about human neurology. Mary knows all there is to know about brain activity in color experience. On her twenty-first birthday she leaves her house for the first time. She opens the door to the darkened house and outside sees a multitude of colors everywhere. She knows what her brain is doing when processing these colors but, does she now have additional understanding, knowledge of the qualia involved when humans experience color arrangements?

Sex education, biology and psychology classes might each have something to say about the rapid adolescent heartbeat when kissing a favored friend, and much to say about cascading oxytocin, reinforcement, and operant conditioning but, is there a qualia that is left out of such discussions?

Is it qualia that most importantly needs addressing in socio-sexual education?

Teaching should first and foremost be about what students need to learn and not about what teachers want to teach (Wagner \& Siegel, 1988b; Wagner, 1986). Test alignment on standardized tests focuses on the latter in the name of accountability. Students want what will help them navigate an increasingly complex world of socio-sexual experience - feelings and all.

Biology rightly notes that procreation is necessary for species survival. And students should learn that human sexual behavior comes with both risks and rewards (Jecker, 1993). But those risks and costs entail far more in the socio-sexual world of humans then disease and possibly child raising (Trivers, 1985; Smith, 1982). Even for the bonobo monkey, human's closest primate relative, sexual activity has social consequences extending beyond the biological and economic. With humans, the social elements deepen into psychological, intellectual, and moral reflection and resulting practices as well.

\section{Discovering the Qualia of the Socio-Sexual World}

The sage Homer, observed implicitly, that extended concerns of qualia may "launch a thousand ships". The Trojan War fought allegedly over Prince Paris' affection for Helen's beauty cost much in economic terms and in loss of life and permanent injury to soldiers. Homer's lesson to all of history is that sexual and associative social experiences and evaluations may turn princes into paupers, peasants into princesses, or on the downside, destroy nations, cities, corporations, and careers. Socio-sexual qualia affects much of what every human does with his or her life.

Sexual experience as a field of study in the school curriculum is nowhere near in proportion to the role socio-sexual experience in human life! This oversight persists even though the relevancy of socio-sexual experience for producing "teachable moments" in evident in nearly every subject. In my experience as a consultant in strategic planning with corporations, major hospitals, and universities in years past I found that analogies to marriage or romance often prompted insight on the part of audience (Wagner, 1986). Conversely, when asked by individuals about private romantic dilemmas, I was often able to use analogies to workplace cohesiveness to help someone clear up a private relationship stalemate. In short, not only is the socio-sexual experience ubiquitous in adult life but strategic remedies for conundrums in socio-sexual experience are apt when employed in other social encounters as well and vice versa (Soyer \& Hogarth, 2020). A restrictive silo curriculum of sex education that only specialists teach runs against the experience and reality of adolescence and adulthood both.

Math teachers can teach game theory using socio-sexual examples. History teachers can teach the role of power and action with reckless abandon through stories such as that of Cleopatra and Helen of Troy. Literature courses 
discussing Nathaniel Hawthorne's The Scarlet letter, Soren Kierkegaard's The Seducer's Diary, Leo Tolstoy's Anna Karennia have much to add to student consideration of the socio-sexual experience of life narrative as do the more obvious curriculums such as biology, consumer business and so on (Sternberg, 1998). To exclude the teachable moments socio-sexual experience affords to all these disciplines leaves students poorly prepared for life ahead. Life well-lived is about making deliberate and apt choices (Hogarth, 1987). Life is not about recognizing facts on standardized tests as some faux evaluation of ongoing accountability (Wagner \& Woods, 2020; Wagner \& Freedman, 1985).

The silo surrounding sex education is often airtight. Teachers of other subjects are often fearful of rebuke if they allow class discussion to wander into sexual matters. Metaphorically speaking, too often the word sex like the word God is treated as if it were a four-letter profanity. In short, attention to the qualia of life experience is systematically being neglected in its richness for cross-disciplinary attention.

Matters of an expanded socio-sexual experience should not be treated as indelicacies educators need to tip toe around. Why this happens is captured in Law professor Renata Saleci's claim that "People often use denial and ignorance as useful strategies to deal with an inconvenient truth that does not fit their perception of reality or as tools to create a scenario that makes reality more pleasant and easier to hear $(2020 ; p .22)$ ". As much as any other taboo topic in the sex-silo approach is the idea that moral matters should be addressed.

Like it or not, any human engagement with other humans raises questions about how humans ought to treat one another. These questions cannot reasonably be avoided out of fear of offending someone without at the same time crippling the responsible understanding of students to come to grips with a world that is thoroughly social through and through.

\section{Morality is Unavoidable in Socio-Sexual Experience}

Local and general culture undeniably shape many attitudes, values, and social conventions of people. But as noted above, while culture matters it is not all that matters. There is more; genetics, evolutionary tendencies, confounding qualia (as Blaise Pascal opined in his Pensées, "The heart has its reasons the mind knows not. (1995)". And sometimes education does the right thing when challenging the cultural status quo as it did with instruction on minority rights and the "me-too" movement when the surrounding culture was generally unaccepting of such values (Saleci, 2020).

Human intuition is surely in agreement that there are no exhaustive operational definitions of love (Soble, 1990). Social scientists working in this area are jousting at windmills at least in the minds of most people's common perceptions. On the other hand, people may generally agree that love, whatever else it may be, is a very special emotion categorically distinct from nearly any other emotion. It has a unique qualia of which people can become conscious (Fowers, Lyons, Montel, \& Shakel, 2001).

Free of silo restrictions socio-sexual education should prudentially acknowledge that in the socio-sexual sub-game of romance, love, though ill-defined, is typically valued above all else in the socio-sexual world and for good evolutionary reason. This evolutionary consequence is in line with the intuitions of successfully coupled adults (Hare \& Woods, 2020).

There is a difference between morals/ethics which are prescriptions and prohibitions of specific behavior and morality. Morality is acknowledgement of the importance assigned the question "How ought one treat another?" This question may eventuate in morals and other social conventions of etiquette but at its root it is about none of those things but rather about the qualia of individual and communal life (Wagner, 1983). The question does not lead necessarily into either religious or metaphysical speculation of the truth of morals nor the source of such truth. Neither does response to the question exclude the importance of such questions for individuals. All can be accommodated by reflecting on the evolutionary source of morality.

Morality stems from the instinct to cooperate. All herd animals have as an evolutionary asset the impulse to cooperate. From zebras to the pride of lions who hunt them, cooperation invigorates species survival. In contrast, cooperation is not found among some animals such as bears, tigers, great white sharks and so on. The latter's evolutionary asset centers more along the lines of individual strength, speed, and such. Herd animals never contemplated and decided to organize as herd animals. They just do. That goes for humans as well as our primate cousins.

Every herd mammal must balance the instinct for self-interest against the instinct for cooperation. How they do that in fact remains a mystery but, they do (Glimcher, 2003). In the case of humans, the evolution of increasingly subtle linguistic skills advancing beyond mere signaling practices amplified cooperative excellence (Wiley, 2015) especially with the invention of the promise. With promising came related cooperative practices including the 
invention of property, currency, inheritance rights and so on. Promising also led to specific architectures for cooperation such as clubs, companies, states, nations, and marriage, courting and parenting rituals. All the latter can be codified by religious institutions but that need not be the case for them to function in regulatory manner among a species destined to be cooperative.

Defectors of course exist in any community but with or with out well-articulated constraints communal herds regulate defectors in their midst. Think of lions, gorillas, and early humans new to life on the African savannah. Human religions, constitutions and traditions amplify protocols for the extension of these instincts, but the instincts are of culture free origination and hence not a matter over which any educator or policy maker need quibble over whose truth about such should trump that of another. The core of morality is ever present in every herd animal. The manifest instinct is part and parcel of human socio-sexual engagement as inherent qualia. This qualia becomes more manifest in the individual's outlook as elements of the individual's phenomenological outlook. Here culture matters but again culture is not all that matters.

Socio-sexual education must take on the challenge of moral matters if it is to forward the understanding of students in any socio-sexual engagement (Wagner, 2020). Defectors from cooperative tolerance are a threat not to arbitrary morals and ethics but to the seriousness with which humans must take the core question. How ought I treat others?

Keep in mind that it is reflection on this question which guides cooperative instinct and not codified recipes for proper behavior moment by moment (Axelrod \& Hamilton, 1981).

\section{Romance Education and the Promise of Love}

Economists may speculate that money makes the world go round and certainly money does give it a spin or two. But a single dollar never launched a thousand ships and Homer tells us this is just what happened in the case of Helen of Troy. The actual historical circumstances surrounding the kidnapping of Helen and the siege of Troy thereafter is not of relevance here. What is of relevance is that the story became a fabled tradition not only of ancient Greece but also of all Western tradition ever since (Ross, 2020). Merely hearing the story may prompt a unique sense of qualia in people. And there are many other romantic tales that elicit similar emotional responsiveness such as Richard Wagner's operatic re-telling of the legend of Tristan and Isolde and historic re-telling in the romantic literature of Peter Abelard and Heloise, Delilah and Samson and others (Ross, 2020). These tales or some modernized version of them continue to make it into nearly every high school curriculum. The socio-sexual world permeates all lived experience from puberty onward.

The social sciences may explain in eloquent, scientific detail why Jose's love for Bizet's Carmen, is simply an unforgiving bit of obsessive-compulsive depression. But scientific explanations do not create an empathetic understanding for what humanists and poets often describe as Jose's, divine madness. The feel of Jose's love and then rejection cannot be captured in the diagnosis of depression. It is not madness Bizet's Jose feels, it is a divine madness. What is divine madness?

The concept of divine madness is more likely explained to students by a humanities instructor attentive to the qualia of human phenomenology than by a social science teacher with such qualia-denying language and substituting instead sterile terms such as obsession or depression. The social science descriptors have their place in socio-sexual education but so too does the reifying language of the humanities. There is a lot to learn about the experience of socio-sexual experience and one course titled sex education simply cannot cover it all.

Students want to know why sexual encounters can be complicated, exhausting, distracting and so confusing. Students want to know why the divine madness feels as it does. They want to know why some seemingly want others fall victim to the divine madness and why it can turn dangerous at times. For example, students understand the need they have to learn why handholding fun with some and uncomfortable with others. Students want to learn how you know when you are in love. Students want to learn if some sexual acts are wrong in any profound sense or only if you or the historical accident of your time and culture says so.

If student sexual understanding is limited to clumsy personal field work, media depictions of grope and grab students are abandoned in their quest for meaningful understanding of socio-sexual experience and all its qualia individuated to each. Even the addition of game theoretic strategies while sharpening their thinking will not illuminate various feels prompted by socio-sexual relations and experience (Wagner, 2017). All this needs to be brought together for anything to be comprehensive socio-sexual education.

In addition to the qualia of experience itself there is a phenomenology of sexual arousal, a phenomenology of approaching orgasm, a phenomenology of romance and a phenomenology of love (Scruton, 1986; Soble, 1990; Wilson, 1995, 1980). Together these phenomenology's are what living agents know about qualia from the inside. What does it mean to know the phenomenology of experiences from the inside that together comprise the qualia of 
lived experience?

Consider this. There are some very competent male, obstetric/gynecologists who know a great deal about the bodies of women and the process of arousal, orgasm, childbirth and so on. But knowledge alone is about the mechanisms of patients' bodies. Such knowledge does not translate into understanding what specific patient experiences from the inside in each case. The phenomenology of women's experience is private and forever beyond the range of male doctor's understanding. A male doctor can only know about a woman's physiology but, he can never understand the phenomenology of the experience as she sees it from within the experience itself. The questions students' want answered about sexual arousal, romance and love are questions to be answered from the inside out. Unfortunately, no literal explanations can sum things up adequately. Instead advance into the qualia of another's experience occurs through the metaphorical and analogical accounts of phenomenological aspects are the best that can be achieved and the humanities are well suited for this aspect of reflection into the socio-sexual world (Wagner \& Len Brink, 1979).

Typical sex educators do not trade in metaphor and analogy. But that does not mean that education should not provide students with an opportunity to reflect on these matters universally experienced but individuated in feel. Fortunately, as Catherine Elgin (1999) assures every full person, "We don't have to know what our emotions are to have our world structured by them." By admitting the arts and humanities into the sex education curriculum, sex educators extend students' socio-sexual understanding even if the understanding can never be fully complete.

Through allegory, fable, analogy, artistic depiction and so on, the arts and humanities illuminate the phenomenology of human socio-sexual experience and through that inspire sympathies and empathies and illuminating perhaps some sense of shared qualia.

No one doubts that different readers get a very different take on Leo Tolstoy's (2003) Anna Karenina. But, often, readers get sufficient shared takes on the book that may prompt shared respect for the qualia of Anna's experience, and this may be shared with other soul-searching readers. Of course, not even best of the arts and humanities can reveal all there is to being on the inside looking out at the socio-sexual world of another person, but they can prompt useful imagining uncommon in other more scientific disciplines.

Since the time of Plato's Symposium there has been little systematic effort to write about the phenomenology of sexuality, romance, and love. Artists on the other hand have addressed these topics often. Consider for example, Shakespeare's Sonnets, Elizabeth Barrett Browning's ode, "How Do I Love Thee", Max Ernst's painting, "The Rape", the Ballet La Syphide or Bizet and Puccini's operas Carmen and Madame Butterfly, respectively. And most recently, Wharton School organizational psychologist Adam Grant has enlisted the results of much empirical research to show that there is much practical meaning to be found at the edges of what we can sense in selves and others (Grant, 2021).

\section{Personhood and Sexuality Morality}

Socio-sexual education is about persons engaging other persons. This is quite different from bodies encountering other bodies. The serious study of personhood began with Immanuel Kant. But the study of personhood languished until the 1970s when advances in medicine made the concept of personhood central to the burgeoning field of medical ethics (Engelhardt, 1990). What makes a person more than the meat of the body? And why do persons owe something to other persons that is not owed to mere animated meat?

Animated meat is insufficient evidence for identifying a body as a person, a subject of duties and owner of rights (Gazzaniga, 2005). Most societies outlaw incest, pedophilia, and rape as beyond mere civilly unacceptable, sexual behavior. These acts constitute the victimization of another person. They do so by compromising a person's autonomy and its development. It is autonomy as well as the individual's ability to participate in a reciprocal network of rights and duties that shifts one's status from mere biological entity to social participant (i.e., a person). It is autonomy and reciprocal interaction that constitutes personhood (Englehardt, 2000).

Personhood is experienced from the inside (phenomenologically) as self- consciousness (Chalmers, 2010; Edelman, 2004). Recognition of one's own and other's personhood constitutes moral and legal status exceeding anything describable solely in biological terms (Buss, 1988). Many animals engage in copulation but only humans engage in romance, love and what herein is called socio-sexual experience when one person singles out another for special attention sexually arousing to either or both. Other mammals can be caring and protective but is that the same as human romance, love, and socio-sexual experience? How could we know? Is that not like asking what it is like to be a bat? 


\section{Socio-Sexual Arousal}

Imagine a youth reaching to place a hand on the shoulder of another. Imagine this is a welcomed gesture and sexually stimulating to the other. Now imagine the person touched discovers it was from the person behind the couple. With anticipation of the meaning of the initial gesture, the immediate tactile and kinetic sensation is arousing. However, upon recognizing the stimulation is caused by someone other than one's companion is unsettling. There is a disconnect between the cause and the qualia of stimulation. Scruton suggest it makes no difference whether the interloper is drop-dead desirable or repulsive. In each case the discovery that the physical stimulation is caused by someone other than expected causes a gap, a void in the experience, an absence of relevant qualia. Following the void, the violated person's response will depend on the impression the violated party then has of the interloper. The void is revealing. What was initially pleasing becomes a phenomenological vacuum, no identifiable feeling of any sort. Biology alone cannot explain such exotic experience (Marks, 2002; Scruton, 1986)! When the interloper is discovered there is not enough time for the brain to record, coordinate and decide to discontinue the pleasant sensation until resolution of the disconnect becomes satisfied (Note 1). Even if the interloper is attractive in the mind of the violated person, the momentary void is what it is until replaced by phenomenally identifiable elements comprising the recovered qualia of the experience a moment later. These phenomenological elements testify to the existence of the qualia and to the fact that sexual arousal is about more than chemistry and psychological reinforcement (Marks, 2002).

Scruton's (1986) thought experiment, prompts students to think more deeply about the question, "Why does kissing some people feel like kissing your own hand while kissing others is exciting?" and, this is the question most likely to prompt early interest is students about to enter a class titled "sex education."

Kissing is not about physiology or, at least not physiology alone. It involves conscious persons to qualify as a kiss (Scruton, 1986). A person may kiss a pet, but no one really knows what it means for a pet to lick (kiss?) a person. Neither biology nor chemistry can explain the different meaning of kisses any more than either can explain the phenomena of self-consciousness of persons (Note 2). Both require explanations from the inside out and science is not in the business of providing such accounts. As cognitive scientist and artificial intelligence researcher Douglas Hofstader (1984) said in his Gödel Escher and Bach, for persons to understand personhood is akin to a hand trying to grab itself.

The phenomenology of kissing can only be approached by turning to concepts of qualia and personhood. Persons are at the very least, social constructs arising from a localized range biological potentialities (Scruton, 1986). One person's kiss may capture the imagination and attention of another more than that of any rival. There is a whole myriad of reasons why this may be so. Some of these reasons presumably have to do with the engagement of persons and can only be felt by those involved and understood by other persons only in part and analogically. Persons make kisses mean a variety of different things. People may kiss politely to greet another, to express familial bondedness, to comfort another, to sexually arouse another, to betray another and to dismiss another.

Because persons are what they are and kisses are what they are, the potential meaningfulness of kisses situates them as a paradigm of meaning-making qualia in socio-sexual experience.

Admittedly no one can know what is in another's mind at the time of a kiss or some other sexual act. But one can know roughly what is in one's own mind. As noted above, persons in any social situation confront cooperate/defect challenges. For example, persons generally believe that giving either a meaningful or a meaningless kiss affects the mindset and perhaps the behavior of the person kissed. People sensuously engaged will notice that something good or bad, pleasant, or unpleasant - is underway. The qualia of the experience are palpably real to the participants.

Each person's conscious sense of the gestalt musters together all that is involved in sexual arousal from the necessary biological conditions to psychological reinforcement and the phenomenological elements of the qualia. The intent of people kissing determines much of the qualia in romantic kissing.

The tale of romantic kissing is an experience students are eager to understand. It is the qualia of the socio-cultural experience of romance, kissing and so on students hope will be revealed through appropriate education. Such guided narrative and reflection may limit the disappointment associated with reckless and imprudent behavior in all sorts of socio-sexual matters for some.

\section{The Qualia, Limits, and Insights}

In many ways kissing not intercourse is the crown jewel of sexual arousal and perhaps, the crown jewel of both romance and love. Nearly anything that can be said of kissing can be said of every sexual encounter. Moreover, as the kiss goes, so goes what follows in many cases. Meaningless kisses at best lead only to meaningless intercourse. 
Kisses, not intercourse, are the gateway to romance. A meaningful kiss reciprocated leads to anticipation setting off all the whistles and bells of romantic qualia. Students should learn that those who ignore the meaning of a kiss are in peril of unexpected rejection, embarrassment, or some other compromising experience such as pointless intercourse. "Embarrassment" and "compromising" are used here deliberately as predicates of socio-sexual qualia.

A socio-sexual experience gone wrong may in the worse cases lead to depression. Pediatrician Meg Meeker (2001) describes depression as the most widely reported STD. Depression often happens, she claims when children do not pay attention to the meaning of their own kisses and those of the people who kiss them. Students can learn of romantic depression without having to suffer the worse of it. Literature for example can introduce readers to the qualia of some human experiences that social sciences cannot explain. Consider for example high school students reading Count Leo Tolstoy's Anna Karenina. Anna marries a fine gentleman but has no romantic feelings towards him. She later becomes smitten with a dashing count who wants only meaningless sex with no burden of attachment. Anna invests herself in the count. She comes to despise her husband and leaves him She then is left by the count and finds herself without any socio-sexual moorings and becomes depressed. She feels she has lost herself and so, ends her own life by stepping in front of a train. As Meeker warns, the depression accompanying socio-sexual experience gone badly wrong can be devastating to the young. What could be a more important lesson to learn through socio-sex education?

The artist's divine madness is part of the qualia students want to learn about. The kiss of sexual appetite awakens the most peculiar of all appetites namely, the sexual appetite.

In contrast to the sexual appetite, the hunger appetite diminishes with a bit of food, so too thirst diminishes with a bit of drink. None of this is so with the kiss of sexual appetite. Its qualia are notably different from the qualia of mere physical appetites. The kiss of sexual arousal increases appetite rather than diminishes it (Scruton, 1986). If one person ignores the other's need, the hoped for sharing of qualia and cooperation loses out to the interests of the defector (Soble, 1990). Paying attention to boundaries helps each partner understand the other's qualia. Signaling one's sense of personal qualia is an alert to be heeded for better or worse. Even teens recognize humans are different from agents of mere algorithmic intelligence.

Students want to learn as Anna Karenina never did, that passionate fervor may be sharply different from the experience of romantically shared qualia. Instruction limited to the function of copulating machinery cannot teach this distinction. Similarly, lessons learned from Hester Primm's experience in Nathaniel Hawthorne's The Scarlet Letter can be revealing when confronted forth-rightly as a socio-sexual moral tale and not merely one of sociorecklessness or the innocence (Pearl) of pure lovemaking.

\section{Even Philosophy Has a Proper Role in Socio-Sexual Education}

In philosophy for children lessons I managed with students on and off for nearly thirty years it was my experience to routinely witness students in junior and senior high schools stirred by such imaginings as provided above by authors such as Tolstoy, Hawthorne, Kierkegaard, and others (Wagner, 1979). In the right context, even Soren Kierkegaard's The Seducer's Diary (2013) and other romantic literature including classic operas such as Bizet, Puccini, Wagner can reveal to students the missing element of qualia so often over-looked in formally labelled classes in sex education.

Teen boys, every bit as much as teen girls, are stirred by the question, "What is love?" Yet where can teens turn for an answer to this phenomenological question as opposed to faux answers offered on empirical grounds alone? First, teens should probably be advised to turn off television and avoid movies that is if they are trying genuinely to get a fix on the phenomenology involved in the qualia-making experience of love and romance. Second, unlike as in the past, children might have turned to parents for an answer only to be disappointed by the words, "When you're in love, you'll know it". For teens just trying to get a foothold in the socio-sexual world of love and romance, this response is not enough (Kross, 2021), though it probably hints more accurately at a responsible answer than what is shown in many movies and television shows, beyond say, The Notebook, The English Patient, and On Golden Pond.

The Dallas Morning News ran a piece on love and romance nearly twenty years ago. This piece can still be found as a teaching resource as an appendix in a book titled Focus on Teaching (Wagner et al., 2017). "According to the newspaper's feature story, the central element of love - as opposed to mere romance - is the ability to give, to be altruistic towards others, especially to the beloved. Ability should be distinguished from mere capacity (McCullough, 2020). Ability is developed from capacity. In this case the capacity for love is evident in most people's childhood. But for that capacity to serve as a platform for the experience of romance there must be ability-developing experiences that nurture emerging ability to love romantically and to feel loved romantically. 
Romance is no mere physiological event. Students can easily imagine in a socio-sexual context a distinct difference between romance and faux romance. Instruction across the curriculum can help them imagine this difference. For example, in faux romance, what looks like giving is often a tactic for getting, that is, a manipulation intended to secure control over another" (Wagner, 2000). Is not such manipulation a common storyline in many electronic media presentations?

Even in reality television programming such as "Bachelor Nation" programming touting candidates falling in love, more often than not the strategy to "win" by getting a rose is at the heart of every round of play. In contrast, in the Dallas Morning News article the author notes that in volunteer work at M.D. Anderson Cancer Center love was often palpably felt just walking into patients' rooms and see a healthy spouse in bed with the beloved patient. Each knew the time-horizon for hugging was diminishing beyond reach. For such couples, the Cancer Center sometimes led them to recognize that "Love is not easy to come by...." To experience love you must know how to give unselfishly and, truly how to treasure gifts given to you. For example, the tears of a beloved during a moment of tenderness are more beautiful and dramatic when gracing a cheek than any jewelry adorning a throat or a wrist" (Wagner, 2000). Again, artistry and literature are key to going beyond standard fare in sex education and understanding socio-sexual qualia.

Sex education should be practical, genuinely practical, meaning it should address all that goes with being a social/sexual being. The questions students want help answering should have as a place in the curriculum just as much as policy-maker's concerns for addressing social problems such as unwanted pregnancies and disease. Student's need to learn the socio-sexual fabric of lived experience ahead must draw fully on all available instructional resources across the curriculum.

Birth rates among unwed teens was dropping by the turn of the century but rates of STD continued skyrocketing over the previous twenty years (Fortenberry, 2002).

Literature, history, social studies along with mathematical game theory, biology and standard sex education together create socio-sexual education as an on-going field of study; including, the instinctual elements of self-interest as balanced against cooperation and the phenomenological elements that comprise the qualia of all socio-sexual experience.

Selfishness and altruism are both part of the socio-sexual world. They cannot be addressed without acknowledging to students the evolutionary development of human morality and engaging students in dialogue exploring the function of the moral in socio-sexual experience (Wagner, 1986). This is productively conceived as a sort of the species own "self-domestication" (Hare \& Woods, 2020; King, 2020).

\section{Conclusion}

The conclusions should be rather obvious. Sex education nor any other instruction should be contrived to fit into a knowledge silo. Education should always be aligned with the LFTO and be shared through participation in the Great Conversation of Humankind. Socio-sexual experience is threaded throughout life and this is how it should be threaded throughout instruction in public education. All of public education can be mush improved by focusing on the framing problems, decisions and other intellectual challenges and solutions sought in line with the LFTO and not segregated into artificiyal contrivances such as knowledge silos represent.

\section{References}

Ashcroft, C. (2003). Adolescent ambiguities in American pie: popular culture as a resource for sex education. Youth and Society, 35, 1. https://doi.org/10.1177/0044118X03254558

Axelrod, R., \& Hamilton, W. D. (1981) The evolution of cooperation. Science, 211, 1390-1396. https://doi.org/10.1126/science.7466396

Bandura, A. (2006). Toward a psychology of human agency. Perspectives on Psychological Science, 1, 164-80. https://doi.org/10.1111/j.1745-6916.2006.00011.x

Buss, D. (1988). Love acts: the evolutionary biology of love. In R. Sternberg, \& M. Barnes (Eds.), The Psychology of Love (pp. 100-118), New Haven, CT: Yale University Press.

Chalmers, D. (2010). The character of consciousness. New York, NY: Oxford University Press. https://doi.org/10.1093/acprof:oso/9780195311105.001.0001

Edelman, G. (2004). Wider than the sky: The phenomenal gift of consciousness. New Haven, CN: Yale University Press. https://doi.org/10.1172/JCI23795

Elgin, C. (1999). Considered Judgment. Princeton: Princeton University Press. 
Engelhardt, T. (2000). Philosophy of medicine: framing the field. Dordrecht, Holland: Kluwer.

Fowers, B. J., Lyons, E., Montel, K. H., \& Shaked, N., (2001). Positive illusions about marriage among married and single individuals. Journal of Family Psychology, 15(1), 95-109. https://doi.org/10.1037/0893-3200.15.1.95

Fortenberry, J. D. (2002). Unveiling the hidden epidemic of sexually transmitted diseases. Journal of the American Medical Association, 287, 759-769. https://doi.org/10.1001/jama.287.6.768

Gazzaniga, M. (2005). The ethics of neuroscience. New York, NY: Oxford University Press.

Gigerenzer, G. (2014). Risk savvy: How to make good decisions. New York, NY: Viking.

Gilovich, T., Griffin, D., \& Kahneman, D. (2002). Heuristics and biases: The psychology of intuitive judgement. New York, NY: Cambridge University Press. https://doi.org/10.1017/CBO9780511808098

Glimcher, P. (2003). Decisions, uncertainty, and the brain. Cambridge: MIT Press. https://doi.org/10.7551/mitpress/2302.001.0001

Grant, A. (2021). Think again: The power of knowing what you don't know. New York, NY: Viking Pub.

Hare, B., \& Woods, V. (2020). Survival of the friendliness: Understanding our origins and rediscovering our common humanity. New York, NY: Random House.

Hirst, P. (2010). Knowledge and the Curriculum. New York, NY: Routledge.

Hirst, P., \& Peters, R. S. (2011). The logic of education. New York, NY: Routledge. https://doi.org/10.4324/9780203138557

Hofstader, D. (1984). Godel, Esher and Bach. New York: Basic Books.

Hogarth, R. (1987). Judgment and Choice. New York, NY: Wiley.

Jackson, F. (1982). Epiphenomenal qualia. Philosophical Quarterly, 32, 127-36. https://doi.org/10.2307/2960077

Jackson, F. (1998). From metaphysics to ethics: A defense of conceptual analysis. New York, NY: Clarendon Press.

Jecker, N. (1993). Impartiality and special relations. In D. Tietjens-Meyers, et al. (Eds.), Kindred Matters (p. 88). Ithaca, New York: Cornell University Press.

Kahneman, D. (2011). Thinking fast and slow. New York, NY: Farrar, Strauss \& Giroux.

Kierkegaard, S. (2013). The seducer's diary. H.V. Houng, trans. Princeton, NJ: Princeton University Press. https://doi.org/10.1515/9781400847341

King, M. (2020). Social chemistry: Decoding the patterns of human connection. New York, NY: Dutton.

Kross, E. (2021). Chatter: The voice in our head, why it matters and how to harness it. New York, NY: Crown Pub.

Libet, B., \& Kosslyn, S. M. (2004). Mind time: The temporal factor in consciousness. Cambridge, MA: Harvard University Press.

Meeker, M. (2001). Epidemic. Washington DC: Regenery Press.

McCullough, M. E. (2020). The kindness of strangers: How a selfish ape invented a new moral code. New York, NY: Basic Books.

Nagel, T. (1991). Mortal Questions. Cambridge: Cambridge University Press.

Nozick, R. (1989). The Examined Life. New York, NY: Simon and Schuster.

Pollock, J. (1984). How do you maximize expectation value? Nous, 17, 3. https://doi.org/10.2307/2215257

Putnam, H. (1981). "Brains in a vat” In Reason, truth, and history. New York, NY: Cambridge University Press. https://doi.org/10.1017/CBO9780511625398

Ross, A. (2020). Wagnerism: Art, politics in the shadow of music. New York, NY: Farrar, Straus \& Giroux,

Saleci, R. (2020). A passion for ignorance: What we choose not to know and why. Princeton, NJ: Princeton University Press. https://doi.org/10.1515/9780691202020

Scruton, R. (1986). Sexual Desire. New York, NY: Free Press.

Smith, J. M. (1982). Evolution and the theory of games. Cambridge, UK: Cambridge University Press. https://doi.org/10.1017/CBO9780511806292

Soble, A. (1990). The structure of love. New Haven, CN: Yale University Press. 
https://doi.org/10.2307/j.ctt1xp3txp

Soyer, E., \& Hogarth, R. M. (2020). The myth of experience: Why we learn the wrong lessons and ways to correct them. New York, NY: Public Affairs.

Sternberg, R. (1998). Love is a story: A new theory of relationships. New York, NY: Oxford University Press.

Symons, D. (1979). The Evolution of Human Sexuality. New York, NY: Oxford University Press.

Todd, P., \& Miller, G. (1999). From pride to persuasion: saticficing in mate search. In Gigerenzer, G., et. al. (Eds.), Simple heuristics that make us smart (pp. 287-308). Oxford: Oxford University Press.

Tolstoy, L. (2003). Anna Karenina (C. Garnett, Trans.). New York, NY: Barnes and Noble.

Trivers, R. (1985). Social Evolution. San Francisco, CA Benjamins-Cummings Pub.

Wagner, P., \& Len, B. (1979). Philosophy, children and language arts education. Journal of Thought, 4(1) 114-21.

Wagner, P. A., \& Dede, C. (1986). Disciplinary paradigm shifts: A new frontier of futures researchers. World Futures Society Bulletin, 17(2), 25-29.

Wagner, P. A., \& Freedman, G. (1985). Legitimate classes of evidence for identifying effective teaching. Journal of Thought, 7(1), 35-39.

Wagner, P. A., \& Siegel, H. (1988a). Theorizing about human nature. Journal of Thought, 4(1), 109-110.

Wagner, P. A., \& Siegel, H. (1988b). Bias, point of view. Journal of Thought, 10(1), 121-4.

Wagner, P. A., Johnson, D., Fair, F., \& Fasko, D. (2017). Focus on Thinking. New York, NY: Rowman \& Littlefield.

Wagner, P., \& Fair, F. (2020). Education for knowing. Theories of knowledgefor effective student building. New York, NY: Rowman \& Littlefield.

Wagner, P., \& Woods, K. (2020). Historic professions stabilizing the reified image of the law and other historic professions. International Journal of Social Science Studies, 8(1), 1-16. https://doi.org/10.11114/ijsss.v8i6.5024

Wagner, P. A. (1977). Computer power and human reason- from judgement to calculation. Phi Delta Kappan, 59(3) 213.

Wagner, P. (1981). Diverse disciplines afford unique perspectives on basic value questions. Phi Delta Kappan, 62(6), 459-60.

Wagner, P. A. (1983). The idea of a moral person. Journal of Thought, 7(1), 85-96.

Wagner, P. (1986). Philosophical praxis: Rx for psychological well-being. Teaching Philosophy, 9(4), 291-9. https://doi.org/10.5840/teachphil19869460

Wagner, P. A. (1999). Re-engineering the teaching profession. PES Archives, 291-9.

Wagner, P. A. (2000, May 3). From romance to love. Dallas Morning News, p. C2.

Wagner, P. A. (2011). Socio-sexual education: A practical study in formal thinking and teachable moments. Sex Education, 11(02), 193-211. https://doi.org/10.1080/14681811.2011.558427

Wagner, P. A. (2016). Love Trauma. Houston, TX: Third Coast Pub.

Wagner, P. A. (2017). Beyond love trauma. Houston, TX: Third Coast Pub.

Wagner, P. A. (2020). Teaching slow-thinking skills in the face of tribalistic ideologies. International Journal of Social Policy and Education, 2(10), 22-24.

Wiley, R. H. (2015). Noise matters: The evolution of communication. Cambridge, MA: Harvard University Press. https://doi.org/10.4159/9780674287044

Wilson, J. (1995). Love Between Equals. London, UK: Palgrave Macmillan. https://doi.org/10.1007/978-1-349-24253-5

Wilson, J. (1980). Love, Sex and Feminism. St. Louis, MO: Greenwood.

Wolfe, P., \& Blanchette, W. (2003). Sex Education for Students with Disabilities: An Evaluation Guide. Teaching Exceptional Children, 36, 46-57. https://doi.org/10.1177/004005990303600106 


\section{Copyrights}

Copyright for this article is retained by the author(s), with first publication rights granted to the journal.

This is an open-access article distributed under the terms and conditions of the Creative Commons Attribution license (http://creativecommons.org/licenses/by/4.0/). 